Nunt. Antiquus, Belo Horizonte, v. 16, n. 1, p. 271-281, 2020

\title{
Tradução das Bucólicas, de Virgílio: Écloga IX
}

\section{A Translation of Virgil's Ninth Eclogue}

Pedro Barbieri

Universidade de São Paulo (USP), Sâo Paulo, São Paulo / Brasil

pedrobarbieri.antunes@gmail.com

https://orcid.org/0000-0003-2821-9058

Resumo: Apresento uma tradução poética da nona écloga das Bucólicas, de Virgílio, tomando por base o texto da OCT, editado por Mynors (1972). Alguns apontamentos e explicações introduzem o texto.

Palavras-chave: Virgílio; Bucólicas; poesia bucólica; tradução poética.

Abstract: I offer a poetic translation of Virgil's Ninth Eclogue, based on the $O C T$ text edited by Mynors (1972). Some preliminary remarks accompany the text as well as some explanations.

Keywords: Virgil; Eclogues; Pastoral Poetry; Poetic Translation.

\section{Nota introdutória ${ }^{1}$}

Este trabalho faz parte de um projeto de tradução integral das Bucólicas, de Virgílio, que está sendo realizado paulatinamente. A proposta é realizar uma tradução poética e metrificada para todas as composições, sempre em decassílabos. Por ora, os poemas não vêm acompanhados de notas de rodapé, pois, além de haver inúmeros comentários (antigos e modernos) à obra virgiliana, busco antes apresentar os resultados do traslado poético para um público já especializado. Em

\footnotetext{
${ }^{1}$ Agradeço ao parecerista anônimo pela leitura cuidadosa e todos os comentários. Os deslizes remanescentes são de minha responsabilidade.
} 
um segundo momento as versões poderão ser retrabalhadas e mesmo vir acompanhadas de algumas considerações, se for o caso.

A primeira écloga já foi traduzida ${ }^{2}$ e agora apresento o nono poema da obra, uma vez que ele constitui um par temático e lexical com o primeiro (a condição de desterro; o campo e o canto como alívio a este cenário). Considerando justamente a leitura de que ambas as éclogas formam um dístico, além de trasladá-las para o mesmo metro, também busquei trazer a mesma cadência interna para traduzir ambas. Como o decassílabo permite diferentes arranjos rítmicos, ou seja, como há a possibilidade de criar prosódias distintas em um mesmo tipo de verso, optei por adotar uma mesma musicalidade ao primeiro poema e ao nono, com tônicas na segunda sílaba, na quinta, sétima e décima, com uma cesura intermediária.

Assim, para cada hemistíquio, temos um jambo e um anapesto. Como exemplo, veja-se a seguinte fala de Méris (vv. 51-2):

O tempo avia tudo, mesmo o imo. E lembro, amiúde, eu, petiz, cantando ao poente.

Tais versos, seguindo as tônicas e o ritmo proposto, admitem a seguinte leitura:

O / tem / po a / via / tu // do, / mes / mo o i / mo. E / lem / bro, a / miú / de, eu, / pe / tiz, // can / tan / do ao / po / en / te.

A ideia aqui é uma prosódia mista: mais lenta nos tempos fortes e mais rápida nos tempos fracos, em uma tentativa de imitar o hexâmetro e também adequar o verso ao material bucólico, que pode ser ora mais solene ou mesmo lamentoso (a nostalgia da terra perdida), e ora mais despojado e humilde (a placidez das cabrinhas apascentadas). A musicalidade é um dos principais trabalhos por trás desta tradução. Assim, é necessária uma leitura que respeite a prosódia para que o tempo do verso fique bem marcado. Se lemos o v. 51 de forma rápida e monotônica, por exemplo, sem ouvirmos as quantidades de cada sílaba, elas serão pronunciadas como em prosa, de modo que o decassílabo daria lugar a

\footnotetext{
${ }^{2}$ Atualmente no prelo (Revista Caliope).
} 
um dodecassílabo. Todavia, o uso que faço das átonas e principalmente da cesura (remetendo à divisão de hemistíquios do hexâmetro) é importante para o verso. Note-se a escansão de "avia", 3 a pessoa do singular do verbo “aviar”. Como está em uma posição átona, em tempo fraco e rápido, suas duas últimas sílabas podem ser lidas como uma só. ${ }^{3}$ Além disso, a cadência do metro, que é já repetida nos primeiros 50 versos, serve como parâmetro para a leitura também desse trecho, o que ajuda a orientar a prosódia. Assim, as quatro sílabas fortes que proponho (à diferença dos versos heroicos e sáficos) marcam um tempo lento, enquanto as fracas têm um andamento mais ligeiro.

Em alguns trechos, faço uso do registro mais simples, próprio do original, como o uso de diminutivos. Mas também recorro a algum vocabulário incomum, o que não deixa de estar em sintonia com Virgílio, uma vez que o seu texto por vezes mistura ambas as formas de elocução, em especial com o uso de hipérbatos, zeugmas, jogos sonoros e intertextualidades em algumas passagens. Afinal, a ficcionalização da fala simples é em si um produto da erudição, que a emula, estabelecendo certo distanciamento e tensão entre o poeta e o seu objeto, como era também o caso dos seus modelos gregos. ${ }^{4}$ Deve-se aqui reconhecer que a simplicidade do poema virgiliano é uma idealização e, portanto, fruto da artificialidade do compositor, tanto na matéria quanto na língua. $\mathrm{O}$ confisco de terras, por exemplo, pode tanto ser lido como um comentário político aos eventos de então, como ainda a nostalgia de um tempo remoto, com a provável sobreposição de ambas as camadas. ${ }^{5} \mathrm{O}$ nome de Títiro, que aparece no v. 24, é envolto em alusões, ${ }^{6}$ ao passo que a menção a Dáfnis no v. 50 faz uso de um eco sonoro bastante sutil (Daph $\underline{n i}$, $\underline{p i}$ ros. :...poma nepotes), o que não deve ser acidental, ao mesmo tempo que implica a narrativa e morte de Dáfnis, como vemos nos Idílios I e VII de

\footnotetext{
${ }^{3}$ Por outro lado, no verso seguinte, "amiúde" pode ser lido como um trissílabo, como é praxe poeticamente.

${ }^{4}$ Fantuzzi (2006, p. 236-237).

${ }^{5}$ Para o primeiro caso, cf. Liegh (2016, p. 423-424) e Eckerman (2016); para o segundo, Johnston; Papaionannou (2013).

${ }^{6}$ Cf. Paschalis (2008); e, mais uma vez, Eckerman (2016).
} 
Teócrito. ${ }^{7}$ Nesse sentido, a aparente humildade da elocução virgiliana faz uma sombra maior do que esperamos e talvez haja mais invenção em seu poema do que espelhamento. Às vezes o poema vem até nós e às vezes temos que nos esforçar para ir em direção ao poema.

Para a minha tradução, consultei algumas traduções de Virgílio, não apenas para verificar as soluções poéticas já dadas, como no caso de Odorico Mendes (2008) e Raimundo Carvalho (2005), mas também para identificar as interpretações de diferentes tradutores a alguns vocábulos e trechos específicos, recorrendo a Greenough (1900), Fairclough (1916), MacKail (1934) e García \& Ruiz (2008), que costumam seguir o texto original letra a letra.

No mais, segui o texto da OCT, estabelecido por Mynors (1972).

\section{Texto em latim}

\section{Ecloga IX - Lycidas, Moeris}

\section{Lycidas}

te, Moeri, pedes? an, quo via ducit, in urbem?

\section{Moeris}

O Lycida, vivi pervenimus, advena nostri (quod numquam veriti sumus) ut possessor agelli diceret: "Haec mea sunt; veteres migrate coloni!"

5 nunc victi, tristes, quoniam Fors omnia versat, hos illi-quod nec vertat bene-mittimus haedos.

\section{Lycidas}

Certe equidem audieram, qua se subducere colles incipiunt, mollique iugum demittere clivo, usque ad aquam et veteres (iam fracta cacumina) fagos

10 omnia carminibus vestrum servasse Menalcan.

\footnotetext{
${ }^{7}$ Gagliardi (2019, em especial p. 129).
} 


\section{Moeris}

Audieras, et fama fuit; sed carmina tantum nostra valent, Lycida, tela inter Martia, quantum

Chaonias dicunt aquila veniente columbas. quod nisi me quacumque novas incidere lites

15 ante Sinistra cava monuisset ab ilice cornix, nec tuus hic Moeris, nec viveret ipse Menalcas.

\section{Lycidas}

Heu, cadit in quemquam tantum scelus? Heu, tua nobis paene simul tecum solatia rapta, Menalca? quis caneret nymphas; quis humum florentibus herbis

20 spargeret, aut viridi fontes induceret umbra? vel quae sublegi tacitus tibi carmina nuper, cum te ad delicias ferres, Amaryllida, nostras? Tityre, dum redeo-brevis est via-pasce capellas, et potum pastas age, Tityre, et inter agendum

25 occursare capro, cornu ferit ille, caveto.

\section{Moeris}

Immo haec, quae Varo necdum perfecta canebat:

"Vare, tuum nomen, superet modo Mantua nobisMantua, vae miserae nimium vicina Cremonaecantantes sublime ferent ad sidera cycni."

\section{Lycidas}

30 Sic tua Cyrneas fugiant examina taxos; sic cytiso pastae distendant ubera vaccae! Incipe, si quid habes: et me fecere poetam Pierides; sunt et mihi carmina; me quoque dicunt vatem pastores, sed non ego credulus illis.

35 Nam neque adhuc Vario videor, nec dicere Cinna digna, sed argutos inter strepere anser olores. 


\section{Moeris}

Id quidem ago et tacitus, Lycida, mecum ipse voluto, si valeam meminisse; neque est ignobile carmen: huc ades, $O$ Galatea; quis est nam ludus in undis

40 hic ver purpureum; varios hic flumina circum fundit humus flores; hic candida populus antro imminet, et lentae texunt umbracula vites. huc ades: insani feriant sine litora fluctus.

\section{Lycidas}

Quid, quae te pura solum sub nocte canentem

45 audieram? Numeros memini, si verba tenerem.

"Daphni, quid antiquos signorum suspicis ortus?

Ecce Dionaei processit Caesaris astrum, astrum, quo segetes gauderent frugibus, et quo duceret apricis in collibus uva colorem.

50 insere, Daphni, piros: carpent tua poma nepotes."

\section{Moeris}

Omnia fert aetas, animum quoque: saepe ego longos cantando puerum memini me condere soles: nunc oblita mihi tot carmina; vox quoque Moerim iam fugit ipsa; lupi Moerim videre priores.

55 Sed tamen ista satis referet tibi saepe Menalcas.

\section{Lycidas}

Causando nostros in longum ducis amores: et nunc omne tibi stratum silet aequor, et omnes, aspice, ventosi ceciderunt murmuris aurae. hinc adeo media est nobis via; namque sepulcrum

60 incipit adparere Bianoris: hic ubi densas agricolae stringunt frondes, hic, Moeri, canamus; hic haedos depone: tamen veniemus in urbem. aut si, nox pluviam ne colligat ante, veremur, 
cantantes licet usque (minus via laedit) eamus;

65 cantantes ut eamus, ego hoc te fasce levabo.

\section{Moeris}

Desine plura, puer, et quod nunc instat agamus: carmina tum melius, cum venerit ipse, canemus.

\section{Tradução}

\section{Écloga IX - Lícidas e Méris}

\section{Lícidas}

Teus pés, 'onde vão? À urbe, ó Méris?

Méris

Ó Lícidas, ‘inda em vida vejo outro tomar mi' as terrinhas - nunca temi isso! -, dizendo: "São minhas! Sai, cultor velho!"

5 Coagido e infeliz, pois tudo co' a Sorte se altera, filhotes dou - que não medrem!

\section{Lícidas}

De fato, ouvi que onde enceta o declínio dos cerros e o cimo cai em manso aclive ao rio - velhas faias, copas já gastas -,

10 Menalcas guardou tudo isso com versos.

Méris

Ouviste. É o rumor. Porém nossos versos têm mesmo valor, às lanças marciais, que a pomba caônia à vinda da águia, qual dizem. Se o corvo sestro, em roble oco,

15 não me instruísse o fim do novo conflito, Menalcas nem Méris vivos seriam. 


\section{Lícidas}

Tal crime a quem cabe? Ah, foi teu conforto de nós quase rapto e tu, ó Menalcas? Às ninfas quem canta? E as plantas florentes

20 quem nutre com terra ou véu verde, as fontes?

Quem me há de dar versos quais colhi, oculto, contigo, há pouco, indo à bela Amarílis?

“Até eu voltar - breve é a via - tu pasce as cabrinhas; do pasto, vá ao rio, tu, Títiro;

25 vá co' elas e evita o bode e seu chifre.”

\section{Méris}

Ou tais que cantou a Varo, incompletos:

"Vivendo 'inda Mântua, o teu nome, ó Varo,

- tal Mântua tão junta à pobre Cremona -, será alteado ao céu por cisnes canoros."

\section{Licidas}

30 Que evite a tua abelha os teixos cirneus!

Que o farto laburno encha o ubre da rês!

Se tens algo, enceta! Sou também poeta.

Também tenho versos, graças às Piérias.

Pastores me têm por vate e os descreio.

35 Falei nada digno, qual Cina e Vário, mas, ganso entre cisnes límpidos, grasno.

\section{Méris}

Igual sou. Cismei, silente, em mim, Lícidas, tentando lembrar - não são versos ínfimos:

"Vem, ó Galateia! As ondas te enlevam?

40 Vê o púrp'ra vernal. Cá vários rios cercam o chão que abre em flor. Cá o choupo alvo arqueia ao antro e os vinhais, arqueados, fiam sombras. Vem! Deixa bater, insana, à orla a vaga." 


\section{Licidas}

E aquela que ouvi na noite sem nuvens

45 cantares? Se acerto o dito, eis o metro:

"Ó Dáfnis, vês o orto de idas estrelas?

Vê o astro que advém de César, de Dione:

tal astro dá ao prado o gozo do fruto, dá à uva ter cor no monte insolado!

50 Enxerta os perais, que o pomo é dos netos.”

Méris

O tempo avia tudo, mesmo o imo. E lembro, amiúde, eu, petiz, cantando ao poente.

Tal verso ora olvido. E a voz foge a Méris.

Os lobos já estão defronte a este Méris.

55 Menalcas, porém, trará a ti mais versos.

\section{Licidas}

Avultas meu cor bem mais co' este apelo.

Ora o amplo mar todo cala e ora te ouve.

Eis, todas as brisas cessam 's murmúrios.

Metade da senda foi-se. E Bianor

60 surge em seu sepulcro - aqui os cultores aparam as folhas densas. Cantemos!

Detém cá os cabritos! Logo à urbe iremos.

Se há medo que a noite traga antes chuva, sigamos cantando - adeus, tédio à senda! -,

65 sigamos cantando, e teu fardo abrando!

Méris

Não mais, jovem! Basta! O urgente nos chama.

Vindo o outro, um melhor poema entoaremos. 


\section{Referências}

ECKERMAN, C. Freedom and Slavery in Vergil's Eclogue 1. Wiener Studien, Vienna, v. 129, p. 257-280, 2016. DOI: https://doi.org/10.1553/ wst129s257.

FANTUZZI, M. Theocritus' Cooperative Interpreters, and the Creation of a Bucolic Reader. In: FANTUZZI, M.; PAPANGHELIS, T. (ed.). $A$ Companion to Greek and Latin Pastoral. Leiden/Boston: Brill, 2006. p. 235-262. DOI: https://doi.org/10.1163/9789047408536_011.

GAGLIARDI, P. The Metamorphosis of Daphnis from Theocritus to Virgil. Phasis, Tbilisi, v. 21-22, p. 119-139, 2019.

JOHNSTON, P. A.; PAPAIOANNOU, S. Introduction: Idyllic Landscapes in Antiquity: The Golden Age, Arcadia and the Locus Amoenus. Acta Ant. Hung., Budapest, v. 53, p. 133-144, 2013. DOI: https://doi.org/10.1556/ AAnt.53.2013.2-3.1.

LEIGH, M. Vergil's Second Eclogue and the Class Struggle. $C P h$, Chicago, v. 111, p. 406-433, 2016. DOI: https://doi.org/10.1086/688648.

MACKAIL, J. W. (trad.). Virgil's Works: The Aeneid, Eclogues, Georgics. Introduction by Charles L. Durham. New York: The Modern Library, 1934.

MYNORS, R. A. B. (ed.). P. Vergili Maronis: Opera. Oxford: Oxford University Press, 1972.

PASCHALIS, M. Tytirus and Galatea (Virgil, Eclogues 1): An Expected Relationship. Dyctinna, Lille, n. 5, p. 153-169, 2008.

VERGIL. Bucolics, Aeneid, and Georgics of Vergil. Translated by J. B. Greenough. Boston: Ginn \& Co. 1900.

VIRGIL. Eclogues, Georgics, Aeneid 1-6. Translated by H. R. Fairclough. Cambridge: Harvard University Press, 1916. DOI: https://doi.org/10.4159/ DLCL.virgil-eclogues.1916.

VIRGILIO. Bucólicas, Geórgicas, Apéndice Virgiliano. Introducción general por J. L. Vidal. Traducciones, introduciones y notas por Tomás de la Ascención Recio García y Arturo Soler Ruiz. Madrid: Editorial Gredos, 2008. 
VIRGÍLIO. Bucólicas. Tradução de Manuel Odorico Mendes. Edição anotada e comentada pelo Grupo de Trabalho Odorico Mendes. Cotia: Ateliê Editorial; Campinas: Editora Unicamp, 2008.

VIRGÍLIO. Bucólicas: edição bilíngue. Tradução de Raimundo Carvalho. Belo Horizonte: Crisálida, 2005.

Recebido em: 28 de maio de 2020. Aprovado em: 9 de julho de 2020. 